\title{
ESCOLAS DE SAMBA CARIOCAS A BUSCA DA VITÓRIA NOS DESFILES E NA COMUNICAÇÃO
}

\author{
Mirian Martins da Motta Magalhães
}

Analisa a importância da comunicação, mais precisamente da boa comunicação face a face que ocorre nas interações entre os diferentes atores que compõem as agremiações carnavalescas do Grupo Especial do Rio de Janeiro. A pesquisa identificou como ponto-chave para a organização do desfile carnavalesco o discurso dos diferentes agentes, o que nem sempre é compreendido da forma desejada. Os ruídos são decorrentes da interação de atores com diferentes formações e com bases socioeconômicas e culturais também bastante diversificadas. $O$ desafio enfrentado pela organização do projeto de desfile é constante, cabendo a alguns atores em especial constante negociação com os pares e permanente ajuste do discurso praticado. [abstract on page 279]

ESCOLAS DE SAMBA, CARNAVAL, COMUNICAÇÃO ORGANIZACIONAL. 


\section{INTRODUÇÃO}

O desfile carnavalesco promovido pelas escolas de samba do Grupo Especial é o principal evento da cidade do Rio de Janeiro. Junto com o Réveillon, o carnaval carioca é responsável por $13 \%$ do PIB da cidade proveniente da renda gerada pelo fluxo de turistas que essas duas grandes festas mobilizam.

Só o carnaval cria 500 mil postos de trabalho, formais e informais, diretamente ligados às agremiações carnavalescas ou não, representando para muitos indivíduos a principal fonte de renda. Ainda que os números apontem a grandiosidade e a relevância do evento para a economia local, sua maior expressão, ou pelo menos a mais conhecida, o desfile das escolas de samba do Grupo Especial, guarda modelo organizacional bastante simples e especial em muitos aspectos. A gestão do carnaval conjuga elementos originários do trabalho ordinário com outros, encontrados apenas nos modelos culturais, tornando-se campo bastante fértil e pouco explorado ainda pela pesquisa acadêmica na área da comunicação. Nos institutos universitários da área das ciências humanas, em especial na antropologia e na sociologia, e também na área das artes, o carnaval é assunto muito mais presente nos trabalhos científicos do que naqueles do campo da comunicação.

Especialmente na comunicação organizacional, as escolas de samba são excelentes campos de observação de problemas relativos ao convívio de diferentes atores sociais. Nas agremiações carnavalescas, a base da rede por onde trafegam as informações necessárias para a execução do projeto do desfile é construída através da relação face a face. Essa forma aparentemente elementar de transmissão constitui o principal canal de comunicação em uma escola de samba. Embora muitas agremiações já estejam na era da informática, contando com softwares de simulação, desenhos e retoques auxiliados por programas sofisticados, sites informativos e outras ferramentas tecnológicas, na hora de circular a informação necessária para o projeto de desfile concretizar-se prevalece a veIha e primitiva forma de comunicação: a relação dialógica.

É justamente nesse ponto que as escolas encontram grandes dificuldades. De natureza bastante singular em muitos aspectos e visando atender a essa característica, elas têm buscado um modelo organizacional que prime pela integração de correntes tradicionais e correntes mais progressistas em sua administração. Apesar do esforço e da incansável reformulação organizacional por que têm passado nas últimas décadas, em relação a seu staff, as escolas resguardam sua marca inicial: reunir grupos sociais distintos.

A diversidade socioeconômico-cultural dos agentes que conduzem um projeto de desfile é relevante e de fácil observação em algumas situações, fato que tem gerado problemas sérios de entendimento e percepção, atributos necessários para o alinhamento das decisões. É esse ponto que o artigo irá discutir, buscando compreender a natureza das relações e a origem dos problemas, visando, por meio da reflexão, apontar possíveis caminhos para a resolução desse impasse. Esse esforço ampara-se na compreensão de que o problema não diz respeito apenas aos modelos carnavalescos, sendo também en- 
contrado no trabalho ordinário, uma vez que as organizações produtivas são constituídas por agrupamentos sociais de formação quase sempre diversificada.

\section{QUADRO TEÓRICO-METODOLÓGICO}

A busca de uma teoria da comunicação esbarra na velha separação entre "as redes físicas e imateriais, entre o biológico e o social, a natureza e a cultura, os dispositivos técnicos e o discurso (...), o local e o global, o ator e o sistema, o indivíduo e a sociedade" (MATTELART, 2005, p. 10) que historicamente se deu no interior das diferentes áreas do conhecimento.

Apesar das dificuldades, a comunicação tem lutado pelo status de ciência e por um lugar de destaque nas análises multidisciplinares. Mesmo possuindo todos os contrastes que envolvem as demais ciências, a teoria da comunicação tem marcado presença no mundo acadêmico, em especial pela grande contribuição que a análise de discurso vem dando às questões que envolvem diretamente a observação linguística. Nesse sentido, o olhar etnográfico, desenvolvido nos anos 80 , também proporcionou avanços no entendimento das questões comunicacionais, evidenciando a complexidade do fenômeno, decorrente do fato de ele ocorrer em contextos de socialização.

Além da contribuição da etnografia para as análises comunicacionais, a visão circular do fluxo de informações em detrimento da visão linear, proposta pela Escola de Palo Alto nos anos 40, chamava atenção para a comunicação, ressaltando que ela não deveria ser analisada a partir de um número pequeno e finito de variáveis. Segundo seus defensores:

À noção de comunicação isolada como ato verbal consciente e voluntário, que subjaz à teoria funcionalista, opõe-se a ideia da comunicação como processo social permanente que integra múltiplos modos de comportamento: a fala, o gesto, o olhar, o espaço interindividual (MATTELART, 2005, p. 70).

Nessa linha de pensamento o contexto se sobrepõe ao conteúdo e ressalta as dificuldades culturais, além de destacar as múltiplas linguagens e códigos que há em qualquer processo comunicativo. Os estudiosos pertencentes à Escola de Palo Alto afirmavam então existirem "linguagens silenciosas" próprias de cada cultura, além de lembrar sua responsabilidade nos "choques culturais". Ainda segundo Mattelart (2005, p. 71):

Todas essas linguagens informais encontram-se na origem dos "choques culturais", das incompreensões e mal-entendidos entre as pessoas que não compartilham os mesmos códigos e não atribuem, por exemplo, às regras de organização do espaço e da administração do tempo a mesma significação simbólica.

A corrente francesa da análise de discurso defende que os discursos são decorrentes de práticas sociais apoiadas em contextos histórico-sociais bem definidos (PINTO, 2002). Isso equivale a dizer que as mediações ocorrem em "cenas" conhecidas, porém nem sempre compreendidas. Os embates são repetidos, reapresentados, no entanto, nem sempre assimilados, e, quando são, há sempre novas interferências que originam novos embates. As relações sociais que o modelo carnavalesco proporciona costumam se 
repetir ano após ano, porém os atores participantes não, além de as questões debatidas nem sempre serem as mesmas.

Segundo Pinto (2002, p. 51), "nem todas as situações de comunicação são tão ritualizadas (...) ou gozam de estabilidade"; muito pelo contrário, em muitas ocasiões as mudanças ocorrem a toda hora, desde o tom da voz que se altera até o vocabulário usado, que não é identificável, gerando desconfiança e desconforto nos atores. Nas agremiações carnavalescas, problemas assim são constantes, pois os grupos sociais que são obrigados a interagir costumam possuir bases culturais muito distintas. Além disso, há o fato de a performance carnavalesca exigir níveis de linguagem bastante diferentes e complexos, sendo improvável algum agente envolvido dominar todos com desenvoltura. Entretanto, em alguns momentos, os dirigentes necessitam que sua autoridade seja reconhecida mesmo sem a compreensão total do discurso, senão a execução da tarefa proposta não obterá o resultado desejado. Wander Emediato, em artigo que discute a validação das práticas discursivas, ressalta que "o discurso, nessa perspectiva, é o resultado da busca de acordos sociais que estabilizem as interações, inscrevendo-as em espaços de conformidade e poder" (EMEDIATO ET ALL., 2008, p. 88). Isso significa que os atores devem estar sempre atentos e predispostos à negociação, ou os embates serão frequentes, refletindo-se no desempenho das ações prescritas.

Visando ilustrar esse problema, quando as escolas repassam a sinopse do enredo para os compositores é comum o carnavalesco relacionar palavras que, segundo ele, são centrais, ou seja, expressões que marcam e identificam a essência da proposta do enredo. Porém, essa leitura nem sempre é compartilhada pelos compositores, por diferentes razões: por não serem palavras melódicas, serem difíceis de pronunciar, não serem coloquiais, dificultando a compreensão, entre outras. No livro da antropóloga Maria Laura Cavalcanti, Carnaval: dos bastidores ao desfile, há relatos dos compositores sobre a dificuldade de compreender o enredo:

Não há sinopse que eu não goste, eu gosto de todas elas, o que não gosto é da posição do artista (carnavalesco). Olha, taí (sic) o enredo, eu quero que fale isso e aquilo (...) A sinopse é dos carnavalescos e nós (compositores) fazemos a nossa pesquisa dentro da sinopse deles. Cada um lê de sua maneira e aí vai lá e conversa pra saber se um lance é válido ou não (CAVALCANTI, 1995, p. 104).

Quando o impasse se dá, há necessidade da voz de uma autoridade que tentará mediar, propondo que ambos cedam, até se encontrar um ponto de estabilidade, no qual o trabalho possa ser desenvolvido.

Há uma proposta dentro da teoria organizacional que afirma ser a comunicação o elo entre os diferentes interlocutores, e que ela pode ser extremamente agregadora ou desarticuladora de toda a cadeia produtiva.

O princípio básico que norteia essa proposta está alicerçado no trabalho de Philip Zarifian (1991), sociólogo francês, cujo estudo está focado na noção de intercompreensão da comunicação. Esse conceito refere-se à linguagem como centro dos processos 
de comunicação, principalmente no mundo do trabalho, em que as falas profissionais são construções sociais da organização.

Zarifian compreende a comunicação em três dimensões: cognitiva, normativa e expressiva. Durante o desenrolar das ações, quando um aspecto desagregador é percebido, cognitivamente o responsável toma uma decisão voltada para eliminá-lo. No entanto, o que o faz escolher aquela decisão é a lógica subjacente ao processo, à prescrição de que aquele movimento favorecerá o desempenho almejado (dimensão normativa). E mais, sua decisão também deverá estar amparada em seu envolvimento com aquela organização, que transcende as barreiras profissionais (dimensão expressiva). Por isso conhecer a cultura organizacional é fundamental: o que funciona para uns não funciona para outros (SALERNO, 1999).

Conforme a proposta, os alicerces organizacionais estão na boa comunicação, pois se ela falha prejudica todo o processo. Ainda dentro dessa concepção teórica, em organizações que resguardam configurações únicas (fora do contexto clássico organizacional), como é o caso das agremiações carnavalescas, esse olhar é bem-vindo e, mais do que isso, bastante adaptável. Segundo Mário Salerno (1999, p. 72), que dedicou um livro a esse modelo organizacional (nomeado por ele "organizações flexíveis"),

a gestão de organizações flexíveis no contexto do trabalho ordinário pressupõe a inovação do produto ou do processo, que responde pela competitividade. Estas organizações têm como características, além da inovação, trabalho organizado em grupos semiautônomos, coordenação horizontal e novos papéis extrapolando os de referência.

A metodologia usada para a pesquisa desenvolvida tomou como garantia conceitos interpretativistas de base fenomenológica, como os difundidos pela etnometodologia e o interacionismo simbólico. A etnometodologia, que tem como precursor Harold Garfinkel, analisa as atividades desempenhadas pelos atores através do raciocínio prático que eles demonstram durante as ações. Esse esforço foi realizado com o intuito de manter o mais próximo possível a análise do campo em que ela ocorria, ou seja, deslocandose os discursos sem visualizar sua área de ocorrência, provavelmente perde-se muito em significados (COULON, 1995).

Sendo assim, o mote deste artigo é decorrente da observação realizada para elaboração de dissertação de mestrado, apresentada em 2006 ao Programa de Tecnologia do Cefet/RJ. Para tanto, assisti, em 2004 e 2005, a vários eventos denominados ensaios técnicos, objeto de estudo na ocasião, em diferentes agremiações que compõem o Grupo Especial do carnaval carioca e das quais foi colhido o substrato apresentado neste trabalho.

Embora a base tenha sido extraída dos ensaios presenciados, as reflexões apresentadas neste artigo também são resultado de contínuo aprendizado referente ao universo das escolas de samba cariocas. Atualmente, as pesquisas têm-se voltado para as escolas mirins, instituições que têm como origem as grandes agremiações (escolas- 
mães), mas que lidam com outras proposições além das que envolvem a organização do desfile, como a educação e o resgate da cidadania de crianças e adolescentes.

\section{AS ESCOLAS DE SAMBA}

Os desfiles carnavalescos acontecem desde a década de 1930, porém ao longo do tempo passaram por grandes transformações. Antes eram simples cortejos, em que a distinção entre as alas não era clara, não havia enredo caracterizado, as alegorias eram muito simples comparadas às de hoje, enfim, constituía um espetáculo muito diferente do atual.

Estudiosos do tema reconhecem ciclos de vida bastante definidos na história dos desfiles, havendo apenas algumas discordâncias nas demarcações de suas etapas ou no que de fato proporcionou as transformações em suas características básicas (CAVALCANTI, 1995, CABRAL, 1996). No entanto, há consenso em admitir o processo de modernização da organização do desfile que acometeu as agremiações nos anos 90, inclusive assinalando o deslocamento do foco principal do espetáculo - de atender ao público doméstico para, agora, atender aos turistas estrangeiros e nacionais - como principal direcionador da visão empresarial que tomou conta do evento na fase atual de desenvolvimento (ARAÚJO, 2003).

As organizações carnavalescas foram buscar no trabalho ordinário modelos que pudessem ser adaptados ao seu universo, uma vez que cresceram e começaram a ter problemas comuns a qualquer grande organização produtiva. Dessa forma, o conhecimento já estabelecido apresentava-se como boa alternativa para buscar as soluções. Além disso, a essa altura nas escolas já havia vários profissionais oriundos das mais diferentes áreas, o que favorecia o aprendizado. Naturalmente, algumas técnicas foram sendo inseridas, adaptadas ao mundo carnavalesco, e aquelas que se mostraram viáveis, foram incorporadas, as que não, descartadas.

Apesar de as transformações serem bem-vindas, alguns segmentos mais tradicionais resistiram a certas modernizações. Um exemplo foi a forma como as informações deveriam ser repassadas aos diferentes setores. A interação, a relação face a face foi privilegiada, por ser considerada a forma ideal, a única que resguardava a essência da atividade. As agremiações carnavalescas vivem dialética muito interessante: são representantes de uma cultura secular, contêm elementos das três principais etnias que formam a identidade do povo brasileiro, trabalham sempre com temas (enredos) nacionais, no entanto, realizam apresentações dependentes de tecnologia, utilizando o que há de mais moderno na confecção de espetáculos.

Recentemente, entre outros elementos que lidam com a tecnologia, a iluminação oferecida pela Passarela do Samba (denominação do local da realização dos desfiles no Rio de Janeiro) esteve na berlinda das discussões. Especialmente os carnavalescos, responsáveis artísticos pelo evento, solicitam modificações, alegando que a iluminação utilizada (luz fria) empobrece o resultado estético das apresentações. Esses profissionais, em sua maioria artistas com passagens pela Escola de Belas Artes ou pelo universo teatral, 
possuem conhecimento suficiente para questionar e lutar por uma iluminação diferenciada, que privilegie a concepção artística do projeto de desfile. Segundo informações obtidas através de conversas informais, a luz fria favorece a transmissão para a TV, motivo principal para que ela não fosse mudada.

Essa contenda serve para ilustrar as contradições vividas diariamente nas organizações carnavalescas: o novo e o tradicional convivem, às vezes harmonicamente, outras nem tanto. Além disso, o desfile é evento rentável para diferentes grupos, evidenciando interesses múltiplos, o que faz com que ele sofra forças - favoráveis e desfavoráveis - de todos os lados.

A figura do diretor de carnaval é um bom exemplo de novo agente do carnaval, ou seja, das transformações ocorridas visando à sustentabilidade da expressão. Ele surge nos anos 90, juntamente com o processo de modernização, e se fixa com o estabelecimento da patronagem - a década de 1990 foi o auge do poder dos patronos/banqueiros do jogo do bicho nas agremiações carnavalescas do Rio de Janeiro. Com a instituição dessa função, o diretor de carnaval passa a ser o responsável por coordenar os grupos e direcionar os trabalhos, buscando a eficácia do projeto. As escolas que adotam essa divisão funcional, veem na figura do diretor de carnaval o gerente, aquele que é responsável por todo o projeto, no caso a performance que será apresentada no dia do desfile oficial.

Embora sua competência para a função seja, na maioria das vezes, indiscutível, ele terá que desenvolver mecanismos de comunicação com os demais grupos sociais que compõem a escola, elegendo a melhor linguagem para lidar com um ou com outro. Porém, reforçando o que já foi dito, as agremiações carnavalescas são organizações formadas por grupos sociais distintos, remetendo a uma variedade de linguagens para tratar com os diferentes segmentos, exigindo do diretor de carnaval outra habilidade importante: competência comunicacional.

Essa figura é central no sucesso ou fracasso dos eventos denominados ensaios técnicos, simulações de partes do projeto organizacional do desfile oficial visando ao aperfeiçoamento da performance artística. Naturalmente permeado de estética, o aprimoramento, contudo, atribui prioridade aos fundamentos técnicos (MAGALHÃES, 2006).

Os ensaios técnicos podem ter objetivos variados, como, por exemplo, apenas o aperfeiçoamento de um determinado movimento da escola (a coreografia da comissão de frente) ou a performance coletiva (as simulações realizadas com a maioria dos componentes); no entanto, a motivação é predominantemente de cunho racionalista, embora os elementos relacionados à subjetividade não sejam jamais desprezados pelos dirigentes. A realização desse trabalho compreende desafio permanente, tanto para os componentes que executam os movimentos quanto para os responsáveis por essa simulação, pois aspectos considerados antagônicos são misturados de tal maneira, que se tornam complementares, formando um só corpo, uma só performance (DUFRENNE, 2004).

Por similaridade ao trabalho desenvolvido por Mário Salerno (1999, p. 72) no contexto de organizações flexíveis, a competência comunicacional desses gestores é fun- 
damental na busca da dimensão coletiva do desempenho organizacional, uma vez que ela é responsável pela aplicação e pelo impulso ao "agir orientado ao sucesso", estimulando a expressividade e a criatividade dos componentes durante os ensaios.

Em muitas escolas, no entanto, o diretor é alguém trazido de fora, o que, às vezes, é suficiente para gerar desagrado e desconfiança. Sendo assim, é extremamente importante que o problema de comunicação seja ponderado e que soluções e possíveis caminhos facilitadores sejam encontrados. O conflito é questão constante no trabalho do diretor de carnaval, e para garantir fluxos de aprendizagem satisfatórios é fundamental privilegiar o processo comunicacional, favorecendo-o sempre que possível.

Para tanto, conhecê-lo e analisá-lo em seus diferentes níveis de interação/compreensão e em seus diferentes códigos de utilização é primordial para salvaguardar sua funcionalidade administrativa.

\section{OS PROBLEMAS DE COMUNICAÇÃO}

Durante a pesquisa realizada nas diferentes agremiações, várias falas, provenientes de diversos interlocutores, ressaltavam a questão da comunicação. Um ex-diretor de harmonia lembrou durante uma conversa que o mais complexo numa escola é o fato de serem faladas diferentes línguas e ser necessária a articulação dos diversos grupos sociais durante a confecção do carnaval. Segundo ele, "há reserva de mercado, há preconceito, há divergências sociais, há problemas sérios de comunicação". Em outra ocasião, um aderecista confessou que o mais difícil em seu trabalho era interpretar o enredo, realizá-lo na forma de fantasias, adereços e tudo mais que compõe o carnaval.

Outra lembrança importante que reforça essa dificuldade de comunicação foi descrita por Maria Laura Cavalcanti em seu livro: a ex-carnavalesca Maria Augusta (apud CAVALCANTI, 1995, p. 62) conta como um carnavalesco tem certeza se sua escola vai "acontecer" ou não no desfile: "Quando uma escola chega à avenida, o momento mais importante é o da concentração porque aí é que eles (os desfilantes) vão ver as fantasias uns dos outros. Se gostam das alegorias, a escola cresce, a escola sobe. Se não gostam, o ânimo cai e ninguém põe direito aquela escola na avenida".

Atualmente, o problema apontado por Maria Augusta foi em parte solucionado, pois há uma festa destinada à apresentação do enredo e das fantasias, os protótipos, o que dá uma ideia do que virá. No entanto, essa festa é destinada a poucos, normalmente dirigentes de alas e figuras expressivas da escola, ficando excluída a massa de componentes. Sendo assim, a unidade da narrativa proposta só será vista na avenida, momento que, se for identificado algum ruído de qualquer natureza no processo comunicacional (por exemplo, a proposta do samba é tradicional dissonando da estética vanguardista das fantasias), será tarde para tentar saná-lo.

Maria Laura Cavalcanti ressalta os problemas relativos às diferentes linguagens "faladas" nessas organizações em vários momentos de sua narrativa. Na referida publicação, ela começa um parágrafo da seguinte forma: "A existência de ruídos na comunicação 
e o confronto entre visões de mundo diferenciadas se evidenciam" (CAVALCANTI, 1995, p. 107). O item em que se encontra a frase é relativo ao enredo, a seu desenvolvimento e a sua transposição para a forma carnavalesca. Assim, subentendem-se diferentes tipos de linguagem (composição da letra do samba; criação dos figurinos, elaboração dos carros alegóricos, etc.) a partir de uma narrativa elaborada na forma monográfica (a sinopse), o que só reforça o problema abordado.

Esses exemplos podem parecer ultrapassados em um primeiro momento, pois se encontram-se em edição de 1995; entretanto, durante as observações dos ensaios técnicos, a dificuldade de comunicação entre os atores foi algo recorrente, além das demais dificuldades de entendimento já mencionadas. Os valores do grupo que compõe os ensaios incluem diferentes elementos, cabendo ao diretor de carnaval, no atual modelo de gestão, possuir sensibilidade suficiente para reconhecer esses elementos e desenvolver seu trabalho de acordo com eles. É por isso que quando um dirigente muda de agremiação ele precisa de um tempo para esclarecer à nova comunidade qual é sua metodologia de trabalho. Isso não é feito através de palestras ou cursos, mas sim no próprio espaço destinado à execução das tarefas, sendo verificada, na maioria das escolas, uma evolução, uma aprendizagem organizacional e pessoal (do diretor) nesse processo. No entanto, às vezes, um gesto ou uma palavra inadequada cria barreiras nesse entrosamento, dificultando o entendimento e prejudicando ou mesmo impedindo o desenvolvimento do projeto (GOFFMAN, 2006).

\section{O PROBLEMA E SEU ENTENDIMENTO}

$O$ principal ponto a ser ponderado diz respeito às diferentes linguagens utilizadas na realização de um projeto de desfile. O produto final das organizações carnavalescas é um evento cultural, o desfile oficial, e, como em qualquer produção na área da cultura, a resultante está repleta de significados de diferentes ordens. Para concretizá-lo, é necessário articular diferentes níveis e concepções de linguagem. No projeto de desfile está previsto o arranjo de formas diversas, o que implica complexidade que não pode ser menosprezada. Por exemplo, as dificuldades socioculturais (os diferentes grupos sociais que se cruzam na concepção de um projeto de desfile); as diferentes expressões estéticas (a sinopse do enredo - próxima à expressão/linguagem acadêmica; a feitura de um samba-enredo - próxima à expressão poética; a transformação da história em fantasias e cenografia - próxima à expressão teatral; etc.), todas, no entanto, complementares de uma expressão maior que é a performance carnavalesca.

As escolas de samba, principalmente as que hoje se encontram no Grupo Especial, sofreram profundas modificações ao longo de sua trajetória histórica. A aprendizagem dos dirigentes, referente às novas demandas organizacionais, possibilitando que suas escolas alcançassem o patamar competitivo, foi substancial para a consolidação desse processo. No entanto, a incoerência no processo de gestão não podia deixar de ser considerada, pois a organização do desfile tomava ares profissionais, com planejamento 
estratégico, previsão de gastos, contratação de profissionais qualificados, etc. - ainda havia, como, aliás, haverá sempre, o imponderável, o imprevisto ou o surpreendente.

Observar o desfile através do conceito de performance ajuda no entendimento de aspectos antagônicos, mas que convivem e se equilibram na manutenção do modelo carnavalesco.

Uma compreensão simples do termo performance seria relacioná-la a algo em processo, não podendo e não devendo ser apreciado estaticamente, mas sim no transcorrer das ações. Ela é sempre percebida por um observador e só existe dessa forma, ou seja, é necessário que alguém lhe conceda essa propriedade para ser vista assim (PEIXOTO, 2000).

Uma conceituação do termo mais livre, inspirada no trabalho de Deightond (1992), compreende performance "como o processo de reconhecer os procedimentos organizacionais, avaliar se respondem pela melhor alternativa e, quando não, subvertê-los, apresentando novos procedimentos", que podem ser incorporados ou não à cultura organizacional. Na maioria das vezes, os eventos são únicos e, por isso, os procedimentos normalmente ficam apenas incorporados ao aprendizado dos atores participantes (MAGALHÃES, 2006, p. 23).

Essas conceituações se aplicam à gestão praticada nas escolas de samba, uma vez que essas organizações possuem a inovação como estratégia competitiva, característica que as coloca no contexto das organizações flexíveis; os eventos únicos e inesperados, porém, se apresentam com frequência no universo carnavalesco, obrigando os atores à constante avaliação e/ou revalidação da técnica comunicacional utilizada. Este é o grande desafio, mas também a solução mais eficaz para salvaguardar essa expressão carnavalesca: negociar, encontrar um lugar de mediação, de ajuste das linguagens praticadas, seja nos embates entre os atores visando à execução do projeto, seja nas diferenças propostas e necessárias encontradas nas linguagens utilizadas para compor a performance carnavalesca.

O projeto de organização das escolas de samba cariocas conta com aspectos clássicos de normatização dos processos e de sistematização de tarefas, mas também possui elementos lúdicos, ricos de significados, próprios das expressões artísticas. Conciliar elementos tão díspares não é simples; mas é possível. As apresentações que ocorrem todos os anos têm mostrado isso. Segundo Cavalcanti (1995, p. 25), "as escolas acompanham seu tempo. Sua vitalidade como fenômeno cultural reside na vasta rede de reciprocidade que elas souberam articular, em sua extraordinária capacidade de absorção de elementos e inovação".

\section{CONSIDERAÇÕES FINAIS}

Pesquisar as agremiações carnavalescas foi desafiador, principalmente quando se reconhece que elas não podem ser compreendidas só pela lógica funcionalista, embora apelem para elementos oriundos dessa corrente para obedecer ao projeto de desfile. $\mathrm{E}$ 
continua sendo desafiador, pois é fundamental ao pesquisador despir-se de "pré-conceitos" e, antes de qualquer coisa, preparar-se apenas para identificar, apreender e compreender. E isso não é fácil.

Os modelos organizacionais compostos por elementos e atores tão diferentes são desafiadores não só para quem os observa, mas também para aqueles que o gerenciam e nele atuam, pois estes dois últimos agentes possuem como objetivo o sucesso, clímax bastante complexo quando lembramos que as variáveis que compõem esse universo se originam de raízes diferentes. Objetividade alcançada mediante subjetividade, racionalidade que advém da reprodutibilidade, que, por sua vez, provém de percepção cultivada pela emoção, pela expressividade que o mundo das artes exige.

Para dar conta desse emaranhado de ações, algumas decorrentes da racionalidade mais exacerbada, outras originárias da expressividade e da estética, e alcançar uma situação de consenso, só através de muita compreensão, muita conversação e muito diálogo, o que demanda conhecimento gerado pela integração e reconhecimento dos atores envolvidos nessa constante negociação.

Este trabalho tem como mote a reflexão, até porque, se estamos falando de algo que deve ser constantemente observado e ajustado, não há modelos a propor. O principal objetivo foi chamar atenção para o assunto e alertar para o fato de que atualmente cada vez mais a comunicação terá que lidar com modelos organizacionais nada convencionais, o que provavelmente irá exigir da área no mínimo olhares singulares e novas estratégias para envolver os atores. Sendo assim, o que fica como resultado material da pesquisa é a questão da aprendizagem, que advém de constante observação e decorrente ajuste das ações comunicacionais.

Como relatado, atualmente a investigação tem-se voltado para as agremiações mirins, organizações que têm como proposta outros fins, além da expressão artística. As potencialidades presentes nas agremiações mirins estão focadas nas demandas sociais, na cultura, na mobilização política, na educação e na preocupação com a valorização da criança. Proposta tão audaciosa sem dúvida resultará em muitos ruídos na comunicação, problema só mediado pela troca de experiências e por muito trabalho voltado para os ajustes nos discursos praticados.

\section{REFERÊNCIAS BIBLIOGRÁFICAS}

ARAÚJO, Hiran. Carnaval: seis milênios de história. Rio de Janeiro: Griphus, 2004.

CABRAL, Sérgio. As escolas de samba do Rio de Janeiro. Rio de Janeiro: Lumiar, 1996.

CAVALCANTI, Maria Laura. Carnaval: dos bastidores ao desfile. Rio de Janeiro: Editora UFRJ/MinC/Funarte, 1995.

COULON, Alan. Etnometodologia e educação. Tradução de Guilherme João de Freitas Teixeira. Petrópolis: Vozes, 1995.

DEIGHTOND, John. The Consumption of Performance. Journal of Consumer Research, v. 19, December, 1992.

DUFRENNE, Michel. Estética e filosofia. São Paulo: Perspectiva, 2004. 
EMEDIATO, Wander et al. Análises do discurso hoje. Rio de Janeiro: Editora Nova Fronteira, 2008.

GOFFMAN, Erving. A representação do eu na vida cotidiana. 10a ed., Petrópolis: Vozes, 2002.

MAGALHÃES, Mirian. M. M. A gestão do desempenho nos ensaio técnicos das escolas de samba do Grupo Especial do Rio de Janeiro. Dissertação de Mestrado apresentada ao Programa de Tecnologia do Cefet/RJ, 2006.

MARTTELART, Armand e Michele. História das teorias da comunicação. 8a ed. São Paulo: Edições Loyola, 2005.

PEIXOTO, José Antônio. Análise organizacional na perspectiva do desempenho: uma abordagem contemporânea. Tese de Doutorado apresentada ao Programa de Engenharia de Produção da Coppe, Universidade Federal do Rio de Janeiro, 2002.

PINTO, Milton José. Comunicação e discurso. 2a ed. São Paulo: Hacher Editores, 2002.

SALERNO, Mario Sérgio. Projeto de organizações integradas e flexíveis. São Paulo: Atlas, 1999.

ZARIFIAN, Philippe. Trabalho e comunicação nas indústrias automatizadas. Tempo Social: Revista de Sociologia da USP, v. 3, n. 1-2, 1991, p. 119-130.

Mirian Martins da Motta Magalhães é graduada em jornalismo (1987) e mestre em tecnologia pelo Cefet/RJ (2006). Atualmente é professora do Curso de Comunicação Social do Centro Universitário Augusto Motta e coordena projeto de iniciação científica voltado para o estudo das escolas de samba mirins do Rio de Janeiro.

Artigo recebido em agosto de 2010 e aceito para publicação em setembro 2010. 